Check for updates

Cite this: Chem. Sci., 2018, 9, 9012

๑ All publication charges for this article have been paid for by the Royal Society of Chemistry

Received 6th August 2018

Accepted 2nd October 2018

DOI: $10.1039 / c 8 s c 03493 a$

rsc.li/chemical-science

\section{Metal-free, intermolecular carbopyridylation of alkenes via visible-light-induced reductive radical coupling $\dagger$}

\author{
Dan Chen, Lei Xu, Tianyu Long, Shengqing Zhu, Jun Yang and Lingling Chu (D)*
}

An efficient, metal-free strategy for the intermolecular three-component carbopyridylation of styrenes, enabled by Hantzsch ester and visible light, has been described. This versatile protocol gives access to important $\beta-\mathrm{CF}_{3}$ pyridines, through the regioselective, sequential formation of two $\mathrm{C}-\mathrm{C}$ bonds without the use of exogenous catalysts. The value of this benign protocol has been demonstrated through functionalizations of natural-product- and drug-based complex molecules.
Pyridines are important heterocycles widely found in bioactive natural products, pharmaceuticals, agrochemicals and functional materials. ${ }^{1}$ Top selling pharmaceuticals such as antihistamine drug loratadine and anti-depressant drug mirtazapina contain the pyridine core. Moreover, pyridines are also versatile ligand scaffolds widely employed in the areas of transitionmetal catalysis. ${ }^{2}$ As a result, the development of novel and mild methodologies for the regioselective construction of complex pyridines employing simple starting materials is highly desired.

Alkene-pyridine cross-coupling represents an efficient and powerful strategy to access alkylpyridines with chemo- and regio-selectivity due to the fact that alkenes are simple and abundant building blocks in organic synthesis. ${ }^{3}$ Significant achievement has been made via transition metal catalysis, enabling the efficient intermolecular hydropyridylation of alkenes with pyridines and their derivatives (e.g. $\mathrm{N}$-oxides and $N$-methoxy pyridinium salts). ${ }^{4}$ Recently, several elegant examples, through visible light-induced photoredox catalysis, ${ }^{5}$ of hydropyridylation of alkenes with simple pyridyl halides under mild conditions have been developed. ${ }^{6}$ Nevertheless, carbopyridylation of alkenes, which simultaneously forge two consecutive $\mathrm{C}-\mathrm{C}$ bonds across double bonds and would enable rapid buildup of complex pyridines, is highly desired yet remains a challenge. To date, only a few examples of alkene carbopyridylations have been reported. The Zhu group described the visible-light-mediated fluoroalkyl-heteroarylation of alkenes via an intramolecular heteroaryl ipso-migration, mainly focusing on five-membered heteroaromatic substrates with very few

Center for Advanced Low-dimension Materials, State Key Laboratory for Modification of Chemical Fibers and Polymer Materials, College of Materials Science and Engineering, Donghua University, Shanghai 201620, China.E-mail: lingling.chu1@ dhu.edu.cn

$\dagger$ Electronic supplementary information (ESI) available. See DOI: $10.1039 / \mathrm{c} 8 \mathrm{sc} 03493 \mathrm{a}$ examples of simple pyridines. ${ }^{7}$ Liu and co-worker also developed a Cu-catalyzed trifluoromethylarylation of alkenes, with one pyridine substrate. ${ }^{8}$ Very recently, Su and coworkers reported a visible-light induced carbo-2-pyridylation of electrondeficient alkenes with pyridinium salts via an electron donoracceptor complex. ${ }^{9}$ Nevertheless, these elegant protocols are restricted to two-component mode..$^{7-9} \mathrm{~A}$ general protocol for the intermolecular, three-component carbopyridylation of alkenes has yet to be developed.

In our continuing efforts to pursue radical functionalization of alkenes, ${ }^{10}$ we envisioned that a light-induced, sequential radical-addition/radical-coupling protocol between alkenes and pyridines could provide a generic solution to this challenging carbopyridylation of alkenes. Given the importance of trifluoromethyl groups in pharmaceuticals and agrochemicals ${ }^{11}$ as well as elegant progress in radical trifluoromethylation of alkenes,${ }^{12}$ we focused on the development of pyridyl functionalization of alkenes with concomitant construction of $\mathrm{C}\left(\mathrm{sp}^{3}\right)-$ $\mathrm{CF}_{3}$ bonds. Herein, we reported the intermolecular, threecomponent carbopyridylation of olefins through visible lightinduced reductive radical coupling under transition metal-free conditions (Fig. 1). Particularly, this protocol utilizes the potent redox ability of photoexcited Hantzsch ester (HE) ${ }^{13,14}$ to generate open-shell radical intermediates, thus facilitating the construction of two consecutive $\mathrm{C}-\mathrm{C}$ bonds in one pot without the need for exogenous photocatalysts. Although two elegant examples of intermolecular trifluoromethylarylation of styrenes with arylboronic acids have been described recently, this $\mathrm{Cu}-$ catalyzed platform is inapplicable to heteroarenes. ${ }^{15}$ We expected that our new photo-chemical protocol would complement the known transition-metal protocols.

Inspired by elegant examples of radical coupling with cyanopyridines, ${ }^{13 a, 16}$ we chose cyanopyridines as the coupling partners and Hantzsch ester (HE) as the stoichiometric photoreductant. Irradiating a solution of styrene 2, 4-cyanopyridine 3, 
A) Intramolecular heteroaryl ipso-migration of alkenes<smiles>[R]C(O)(CCC=C)c1ccccn1</smiles>
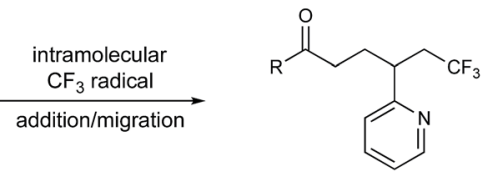

B) This work: Transition-metal-free, intermoleclar carbopyridylation of olefins

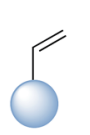<smiles>N#Cc1ccncc1</smiles><smiles>CC1(C)OI(C(F)(F)F)c2ccccc21</smiles>
$\stackrel{\text { hantzsch ester }}{\stackrel{\text { P }}{\longrightarrow}}$
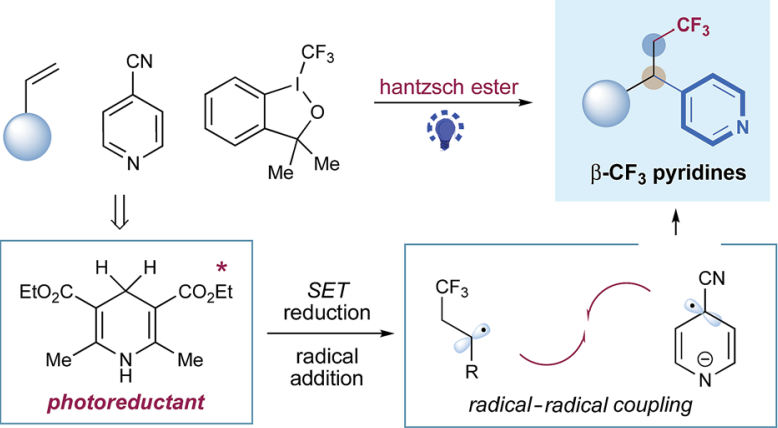

- HE as photoreductant

- Intermolecular \& three-component

- Metal-free \& mild condition

- Sequential radical addition/coupling

Fig. 1 Design of intermolecular carbopyridylation of alkenes via photoexcited Hantzsch ester-enabled reductive radical coupling.

and 3,3-dimethyl-1-(trifluoromethyl)-1,2-benziodoxole 4 (Togni II reagent) in the presence of HE 1 and 1,4-diazabicyclo[2.2.2] octane (DABCO) with a $90 \mathrm{~W}$ blue LED gave the desired trifluoromethylpyridylation product 5 in $83 \%$ yield (Table 1, entry 1). Control experiments indicated that $\mathrm{HE}$ and visible light are required for the reductive coupling, as no products were observed in the absence of HE or under dark conditions (entries 2-4). Notably, DABCO had a dramatic influence on the reaction efficiency. Only $22 \%$ yield of product 5 was observed in the absence of DABCO (entry 5). Employing other organic or inorganic bases instead of DABCO resulted in a dramatic decrease in the reaction efficiency (entries 6-10). Additionally, replacing HE with 4-methyl Hantzsch ester 6, an analog of HE, led to the formation of product $\mathbf{5}$ with a significantly low efficiency (entry 11). Moreover, the choice of the electrophilic trifluoromethylating reagents was also found to have a dramatic effect on the reaction efficiency, with Togni reagent 4 proving to be optimal (entries 12-13).

Having identified the optimal reaction conditions for the visible light-induced reductive pyridylation of alkenes, we investigated the olefin partner using 4-cyanopyridine. As shown in Scheme 1, a variety of styrenes bearing electron-donatingand electron-withdrawing substituents are viable partners for this transformation, affording the corresponding $\beta-\mathrm{CF}_{3}$ pyridines in moderate to excellent yields (products 5 and 9-32, 42$86 \%$ yields). Styrenes containing reactive functional groups, including esters, amides, tosylates, alkynes, and even free amines, underwent the desired coupling with high efficiency (products 5, 16, 18-19, 22, and 29, 58-86\% yields). Notably, the reaction of varied halides, from fluorides to iodides, gave the desired coupling product with halo atoms untouched (products 13-14, 21, 23-25, and 27-28, 65-85\% yields). Halides are important synthetic manipulation handles via transition-metal-
Table 1 Optimization of reaction conditions ${ }^{a}$

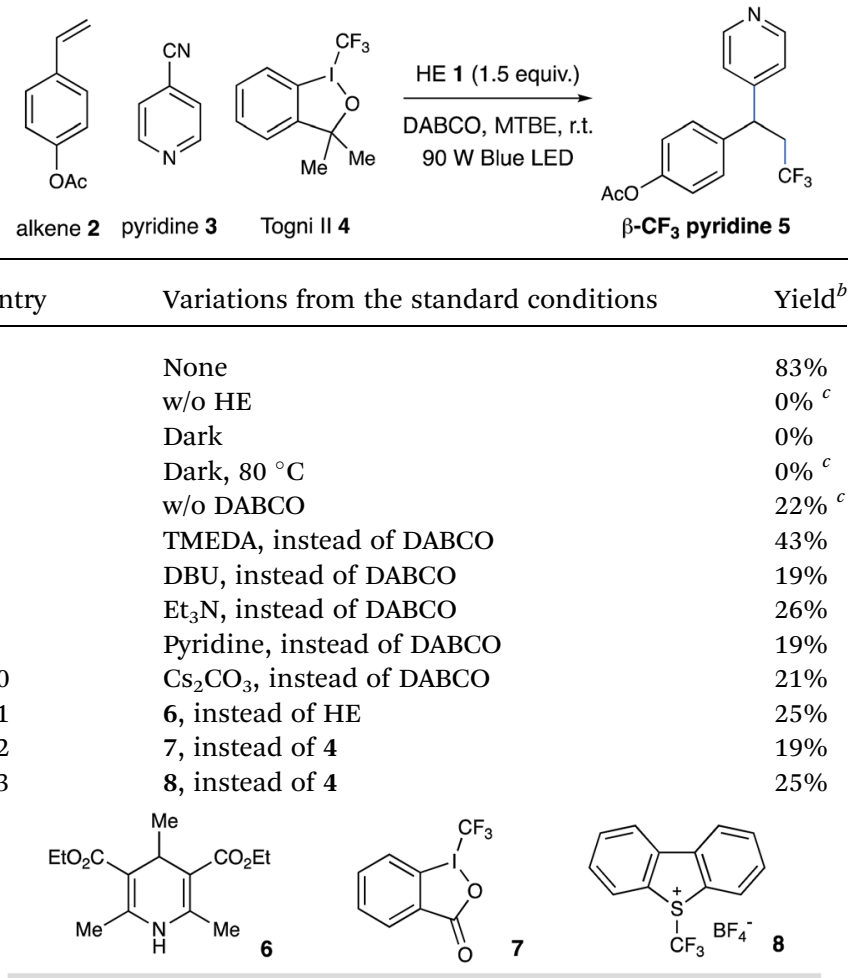

${ }^{a}$ Reaction conditions: styrene $2(0.1 \mathrm{mmol}), 4$-cyanopyridine 3 (2.0 equiv.), Togni reagent 4 (1.5 equiv.), Hantzsch ester (HE, 1.5 equiv.), DABCO (1.5 equiv.), MTBE [0.05 M], $90 \mathrm{~W}$ blue LED, and rt. ${ }^{b}$ Yields were determined by ${ }^{19} \mathrm{~F}$ NMR using an internal standard. ${ }^{c}$ Major byproducts determined were dimers of benzylic radicals; see the ESI for details. DABCO: 1,4-diazabicyclo[2.2.2]octane; MTBE: methyl tertbutyl ether.

catalyzed cross-coupling, further indicating the complementary ability of this visible-light-induced metal-free technique. orthoSubstituents on the aryl rings have little effect on the reaction efficiency (products 23-26, 64-70\% yields). Alkenes attached to electron-deficient arenes, exemplified as 1,2,3,4,5-pentafluoro6-vinylbenzene, were found to be suitable substrates with moderate efficiency (product 31, 42\% yield). Heteroarenes, in the form of indoles, were well tolerated, albeit with lower yields (product 33, 55\% yield). Furthermore, 1,1-disubstituted alkenes, such as $\alpha$-methyl styrene, can be successfully employed, furnishing the expected adducts with moderate efficiency (product 34, 65\% yield). Notably, this threecomponent reductive coupling protocol can be applicable to other types of olefins. Reactions of electron-rich olefins (products 35-36) as well as un-activated alkenes (product 37) furnished the desired trifluoromethylpyridine products with moderate efficiency in the presence of $1 \mathrm{~mol} \%$ of $\operatorname{Ir}(\mathrm{ppy})_{3}(40-$ $52 \%$ yields). We assume that the addition of $\operatorname{Ir}(\mathrm{ppy})_{3}$ could facilitate the single-electron reduction of 4-cyanopyridine, thereby improving the reaction efficiency.

Next, we evaluated the scope of the pyridine component in this metal-free protocol. As illustrated in Scheme 1, substituted 


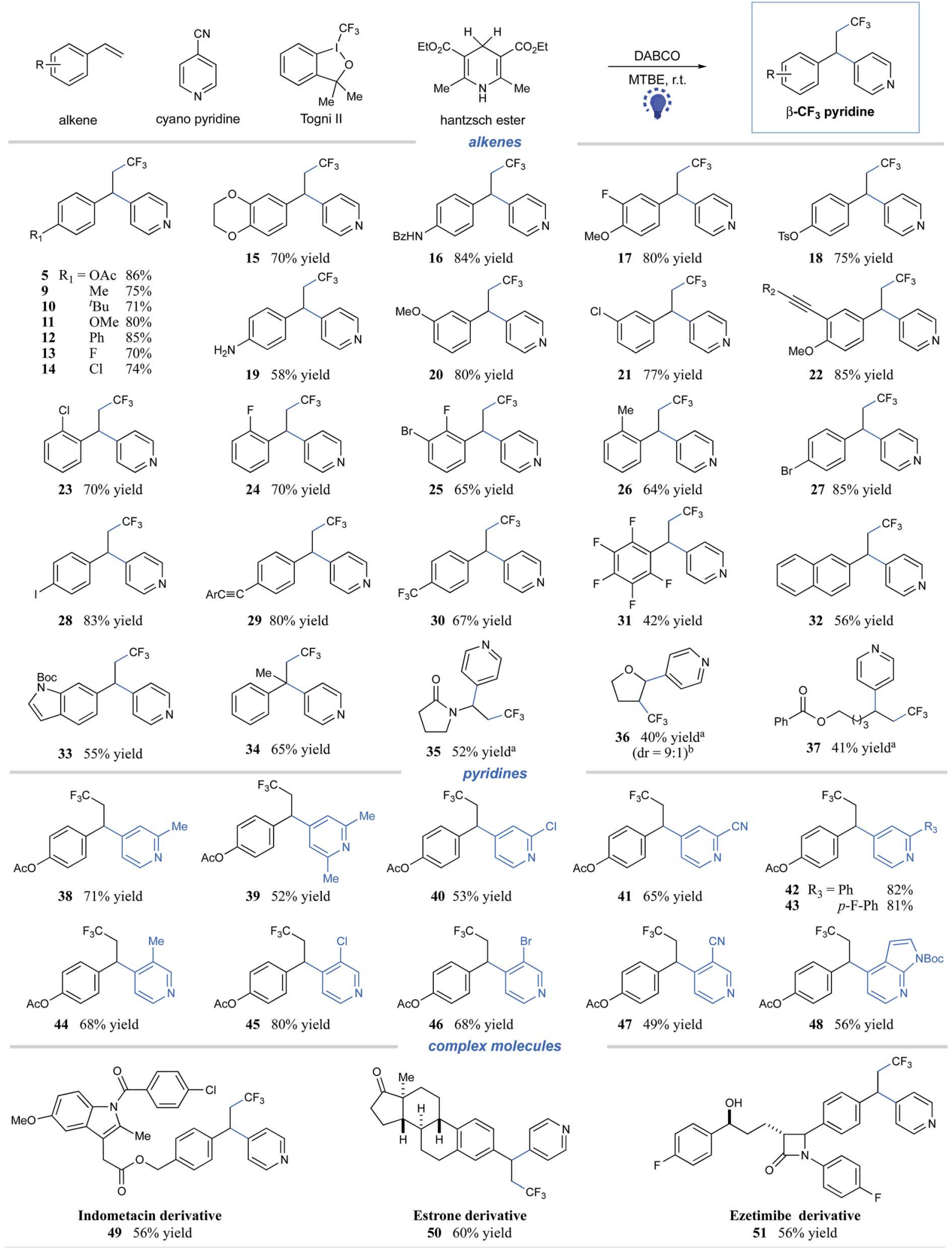

Scheme 1 Substrate scope. Reaction conditions: alkene (0.2 mmol), cyanopyridine (2.0 equiv.), Togni II 4 (1.5 equiv.), HE 1 (1.5 equiv.), DABCO

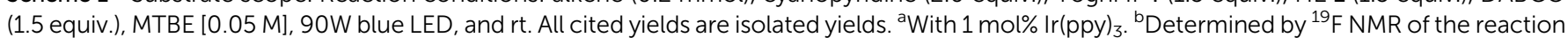
mixture. $R_{2}=n-\mathrm{C}_{4} \mathrm{H}_{9} ; \mathrm{Ar}=$ tert-Bu-phenyl. 
cyanopyridines reacted well under the mild conditions, furnishing the $\beta-\mathrm{CF}_{3}$ alkylpyridines with moderate to high efficiency. A number of substituents on the 2- or 3-position were tolerated, including alkyl, chloro, bromo, aryl, and cyano (products 38-48, 49-82\% yields). Both 2,4- and 3,4-dicyanopyridines underwent selective coupling at the 4-position, affording corresponding 4-alkylated pyridines in synthetically useful yields (products 41 and 47, 65\% and 49\% yields, respectively). Notably, azaindole nitrile was found to readily undergo the desired three-component coupling to afford the alkylated azaindole 48 in satisfactory yield (56\% yield).

To further highlight the potential application of this metalfree protocol, we have employed several natural-product- and drug-derived complex molecules in this system. As depicted in Scheme 1, derivatives of estrone, indomethacin (antiinflammatory drug), ezetimibe (lipid-lowering drug), and nonivamide all functioned as competent coupling partners, furnishing each of the desired adducts with moderate efficiency (products 49-51, 56-60\% yields; S3 in the ESI, $\uparrow$ 55\% yield, see the $\mathrm{ESI} \dagger$ for details).

To probe the mechanism of this alkene carbopyridylation reaction, we have conducted some preliminary mechanistic experiments (Fig. 2). Radical trap and radical clock experiments have been conducted. The addition of TEMPO completely shut down the desired reaction, with the observation of $\mathrm{CF}_{3}-\mathrm{TEMPO}$ adduct 52 (48\% yield) (Fig. 2A). Vinyl cyclopropane 53 underwent radical addition/ring opening, affording $\mathbf{5 4}$ as the major isolated product ( $40 \%$ yield, $E / Z=3.5: 1$ ) (Fig. $2 \mathrm{~B}$ ), further
A)

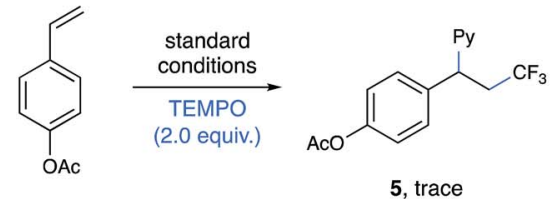

C)

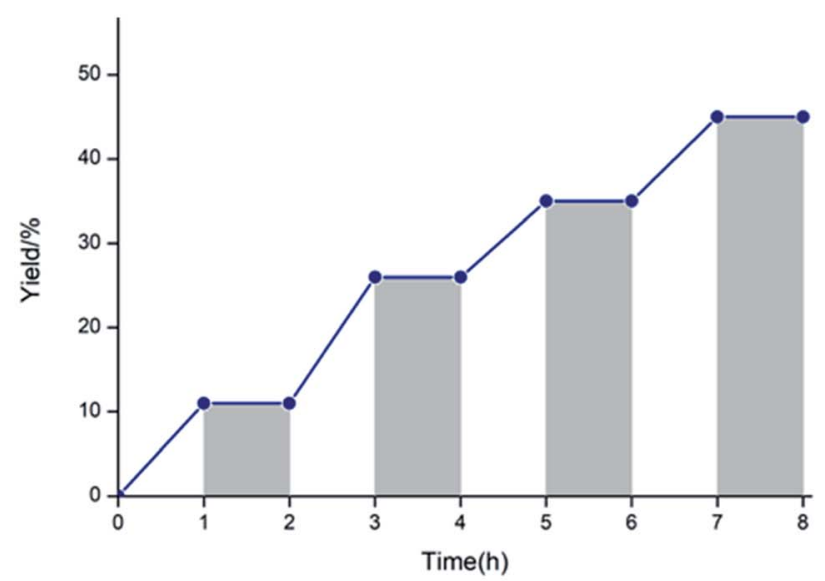

B)

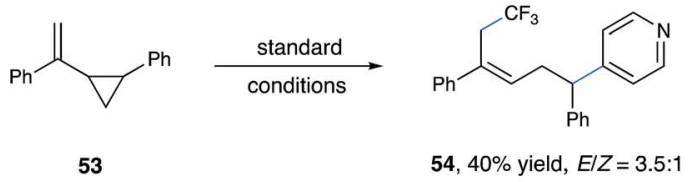

D)

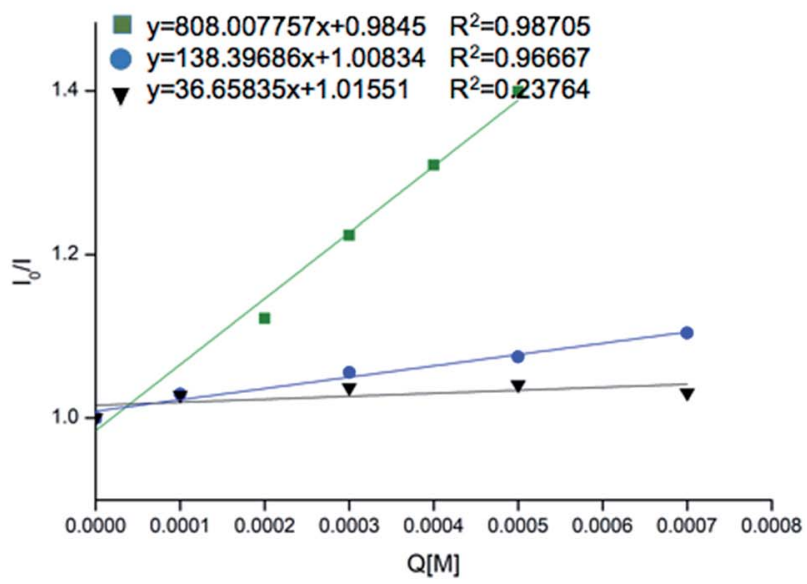

E)

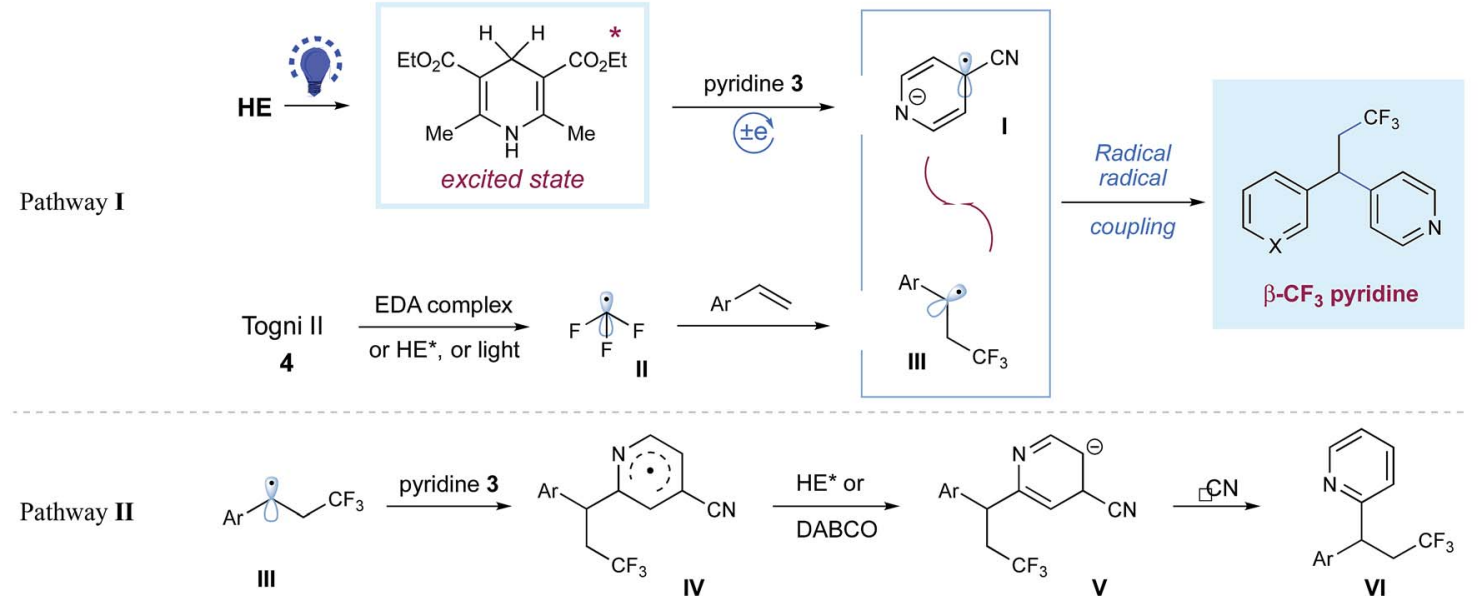

Fig. 2 Mechanistic studies. (A) Radical inhibition reaction. (B) Radical clock reaction. (C) Light on/off experiments; (D) Stern-Volmer quenching studies. (E) Proposed mechanism. 
indicating a radical sequence involved in this novel transformation. Furthermore, light on/off experiments (Fig. 2C), as well as light control experiments (Table 1, entries 3-4), indicated that constant photoirritation is essential for this transformation. In addition, direct illumination of the reaction mixture with a commercial laser $(532 \mathrm{~nm}$, in which HE has no absorption) led to no product formation (see the ESI $\dagger$ for details), suggesting the unique role of the photoexcited HE. Importantly, Stern-Volmer fluorescence quenching analysis indicated that photoexcited $\mathrm{HE}^{*}\left(E_{\mathrm{red}}^{*} \approx-2.2 \mathrm{~V} v s \text {. SCE }\right)^{13 c}$ was quenched by Togni II $4\left(E_{\text {red }}=-1.11 \mathrm{~V} \text { vs. SCE in } \mathrm{CH}_{3} \mathrm{CN}\right)^{17}$ as well as 4-cyanopyridine $3\left(E_{\text {red }}=-1.87 \mathrm{~V} v s\right.$. SCE in $\left.\mathrm{CH}_{3} \mathrm{CN}\right),{ }^{18}$ respectively (Fig. 2D).

On the basis of these experimental results, a proposed mechanism has been exemplified in Fig. 2E. A thermodynamically feasible single-electron reduction between photoexcited $\mathrm{HE}^{*}$ and 4-cyanopyridine 3 would produce the persistent radical anion species $\mathbf{I}$. At the same time, the $\mathrm{CF}_{3}$ radical $\mathbf{I I}$ could be generated through the SET reduction of photoexcited $\mathrm{HE}^{*}$ and Togni reagent 4. Subsequent facile addition of $\mathrm{CF}_{3}$ radical II to styrene led to the formation of the nucleophilic benzylic radical III, which would undergo a selective radical-radical coupling with I to deliver the desired alkylpyridine product via the extrusion of cyanide (pathway I). At this stage, we cannot rule out the possibility that alternative pathways might be involved in this transformation. First, the generation of the $\mathrm{CF}_{3}$ radical could proceed through multiple pathways: (i) triggered by photoexcited HE, which is supported by the Stern-Volmer fluorescence quenching study; (ii) through an electron donoracceptor (EDA) complex between the Togni reagent and DABCO, which is suggested by a bathochromic shift in UV-Vis absorption spectrometry (see Fig. S7 in the ESI $\dagger$ for details); ${ }^{\mathbf{1 9 2 0}}$ (iii) triggered by visible light. Control experiments showed that the major side reactions were dimerization and hydrogen abstraction of benzyl radicals (generated via $\mathrm{CF}_{3}$ radical additions) in the absence of $\mathrm{HE}$ and/or DABCO, while no dimers were observed under the dark conditions (see Table S1 in the ESI $\uparrow$ for more details). These phenomena indicated that visible light could solely promote the generation of the $\mathrm{CF}_{3}$ radical from the Togni reagent. ${ }^{21}$ Second, an alternative pathway might be involved for the coupling step between the benzylic radical and cyanopyridine: nucleophilic addition of benzylic radical III to pyridine 3 at the $\mathrm{C} 2$ position to give rise to aryl radical species IV ${ }^{22}$ radical IV could be reduced by $\mathrm{HE}^{*}$ or DABCO to afford aryl anion $\mathbf{V}$, which undergoes elimination of cyanide to form the C2-substituted product VI (pathway II). Nevertheless, the available experimental results with no observation of VI might not support this hypothesis.

\section{Conclusions}

In conclusion, we have developed an efficient, transition metalfree strategy for the intermolecular, three-component carbopyridylation of styrenes enabled by photoexcited Hantzsch ester. This visible light-induced protocol enables a facile access to $\beta-\mathrm{CF}_{3}$ alkylpyridines, through the regioselective, sequential formation of two $\mathrm{C}-\mathrm{C}$ bonds in one step without the need for exogenous photocatalysts. Given the importance of both pyridine and $\mathrm{CF}_{3}$ moieties in medicinal agents, we expect that the generality of this methodology and ready availability of the starting materials will allow it to enjoy extensive application in the area of organic chemistry.

\section{Conflicts of interest}

There are no conflicts to declare.

\section{Acknowledgements}

We thank the National Natural Science Foundation of China (21702029) and the "Thousand Plan" Youth program and the Shanghai Sailing Program (17YF1400100) for financial support.

\section{Notes and references}

1 (a) E. Vitaku, D. T. Smith and J. T. Njardarson, J. Med. Chem., 2014, 57, 10257; (b) J. J. Li, Heterocyclic Chemistry in Drug Discovery, John Wiley \& Sons, Hoboken, NJ, 2013.

2 M. N. Zafar, A. H. Atif, M. F. Nazar, S. H. Sumrra, E. S. Gul and R. Paracha, Russ. J. Coord. Chem., 2016, 42, 1.

3 Y. Nakao, Synthesis, 2011, 2011, 3209.

4 (a) G. Song, W. N. O. Wylie and Z. Hou, J. Am. Chem. Soc., 2014, 136, 12209; (b) J. Diesel, A. M. Finogenova and N. Cramer, J. Am. Chem. Soc., 2018, 140, 4489; (c) S. D. Friis, M. T. Pirnot and S. L. Buchwald, J. Am. Chem. Soc., 2016, 138, 8372; (d) S. Yu, L. Sang Hui and S. Ge, Angew. Chem., Int. Ed., 2017, 56, 15896; (e) M. W. Gribble Jr., S. Guo and S. L. Buchwald, J. Am. Chem. Soc., 2018, 140, 5057; (f) J. C. Lewis, R. G. Bergman and J. A. Ellman, J. Am. Chem. Soc., 2007, 129, 5332.

5 (a) C. R. J. Stephenson, T. P. Yoon and D. W. C. MacMillan, Visible Light Photocatalysis in Organic Chemistry, Wiley-VCH, 2018; (b) L. Marzo, S. K. Pagire, O. Reiser and B. Konig, Angew. Chem., Int. Ed., 2018, 57, 10034; (c) J. Twilton, C. Le, P. Zhang, M. H. Shaw, R. W. Evans and D. W. C. MacMillan, Nat. Rev. Chem., 2017, 1, 0052; (d) J. K. Matsui, S. B. Lang, D. R. Heitz and G. A. Molander, ACS Catal., 2017, 7, 2563; (e) M. N. Hopkinson, A. TlahuextAca and F. Glorius, Acc. Chem. Res., 2016, 49, 2261; (f) N. A. Romero and D. A. Nicewicz, Chem. Rev., 2016, 116, 10075; $(g) \quad$ C. K. Prier, D. A. Rankic and D. W. C. MacMillan, Chem. Rev., 2013, 113, 5322.

6 (a) R. A. Aycock, D. B. Vogt and N. T. Jui, Chem. Sci., 2017, 8, 7998; (b) A. J. Boyington, M.-L. Y. Riu and N. T. Jui, J. Am. Chem. Soc., 2017, 139, 6582; (c) R. A. Aycock, H. Wang and N. T. Jui, Chem. Sci., 2017, 8, 3121; (d) I. Ghosh, L. Marzo, A. Das, R. Shaikh and B. König, Acc. Chem. Res., 2016, 49, 1566; (e) A. Arora and J. D. Weaver, Acc. Chem. Res., 2016, 49, 2273.

7 (a) Z. Wu, D. Wang, Y. Liu, L. Huan and C. Zhu, J. Am. Chem. Soc., 2017, 139, 1388; (b) J. Yu, D. Wang, Y. Xu, Z. Wu and C. Zhu, Adv. Synth. Catal., 2018, 360, 744.

8 L. Li, Q.-S. Gu, N. Wang, P. Song, Z.-L. Li, X.-H. Li, F.-L. Wang and X.-Y. Liu, Chem. Commun., 2017, 53, 4038. 
9 R. B. Hu, S. Sun and Y. Su, Angew. Chem., Int. Ed., 2017, 56, 10877.

10 J. Sun, P. Li, L. Guo, F. Yu, Y.-P. He and L. Chu, Chem. Commun., 2018, 54, 3162.

11 (a) T. Furuya, A. S. Kamlet and T. Ritter, Nature, 2011, 473, 470; (b) S. Purser, P. R. Moore, S. Swallow and V. Gouverneur, Chem. Soc. Rev., 2008, 37, 320; (c) K. Müller, C. Faeh and F. Diederich, Science, 2007, 317, 1881. 12 (a) C. Alonso, E. Martínez de Marigorta, G. Rubiales and F. Palacios, Chem. Rev., 2015, 115, 1847; (b) J. Charpentier, N. Früh and A. Togni, Chem. Rev., 2015, 115, 650; (c) L. L. Chu and F. L. Qing, Acc. Chem. Res., 2014, 47, 1513; (d) T. Besset, T. Poisson and X. Pannecoucke, Chem.-Eur. J., 2014, 20, 16830; (e) H. Egami and M. Sodeoka, Angew. Chem., Int. Ed., 2014, 53, 8294; (f) E. Merino and C. Nevado, Chem. Soc. Rev., 2014, 43, 6598; (g) T. Liang, C. N. Neumann and T. Ritter, Angew. Chem., Int. Ed., 2013, 52, 8214; (h) A. Studer, Angew. Chem., Int. Ed., 2012, 51, 8950. 13 (a) L. Buzzetti, A. Prieto, S. R. Roy and P. Melchiorre, Angew. Chem., Int. Ed., 2017, 56, 15039; (b) M. A. Emmanuel, N. R. Greenberg, D. G. Oblinsky and T. K. Hyster, Nature, 2016, 540, 414; (c) J. Jung, J. Kim, G. Park, Y. You and E. J. Cho, Adv. Synth. Catal., 2016, 358, 74; (d) W. Chen, H. Tao, W. Huang, G. Wang, S. Li, X. Cheng and G. Li, Chem.-Eur. J., 2016, 22, 9546; (e) L. I. Panferova, A. V. Tsymbal, V. V. Levin, M. I. Struchkova and A. D. Dilman, Org. Lett., 2016, 18, 996; $(f)$ W. Huang, W. Chen, G. Wang, J. Li, X. Cheng and G. Li, ACS Catal., 2016, 6, 7471; (g) J. Zhang, M.-Z. Jin, W. Zhang, L. Yang and Z.-L. Liu, Tetrahedron Lett., 2002, 43, 9687; (h) M.-Z. Jin, L. Yang, L.-M. Wu, Y.-C. Liu and Z.-L. Liu, Chem. Commun., 1998, 2451; (i) S. Fukuzumi, K. Hironaka and T. Tanaka, J. Am. Chem. Soc., 1983, 105, 4722.

14 (a) V. Balzani, P. Ceroni and A. Juris, Photochemistry and Photophysics: Concepts, Research, Applications, Wiley-VCH, 2014; (b) N. J. Turro, V. Ramamurthy and J. C. Scaiano,
Modern Molecular Photochemistry of Organic Molecules, University Science Books, 2010.

15 (a) L. Wu, F. Wang, X. Wan, D. Wang, P. Chen and G. Liu, J. Am. Chem. Soc., 2017, 139, 2904; (b) F. Wang, D. Wang, X. Mu, P. Chen and G. Liu, J. Am. Chem. Soc., 2014, 136, 10202.

16 (a) G. Wang, J. Cao, L. Gao, W. Chen, W. Huang, X. Cheng and S. Li, J. Am. Chem. Soc., 2017, 139, 3904; (b) F. Lima, M. A. Kabeshov, D. N. Tran, C. Battilocchio, J. Sedelmeier, G. Sedelmeier, B. Schenkel and S. V. Ley, Angew. Chem., Int. Ed., 2016, 55, 14085; (c) J. D. Cuthbertson and D. W. C. MacMillan, Nature, 2015, 519, 74; (d) Z. Zuo and D. W. C. MacMillan, J. Am. Chem. Soc., 2014, 136, 5257; (e) K. Qvortrup, D. A. Rankic and D. W. C. MacMillan, J. Am. Chem. Soc., 2014, 136, 626; (f) A. McNally, C. K. Prier and D. W. C. MacMillan, Science, 2011, 334, 1114; (g) D. Mangion and D. R. Arnold, Acc. Chem. Res., 2002, 35, 297; (h) R. Bernardi, T. Caronna, S. Morrocchi and M. Ursini, J. Heterocycl. Chem., 1996, 33, 1137; (i) X. Zeng, J. Cai and Y. Gu, Tetrahedron Lett., 1995, 36, 7275.

17 Y. Yasu, T. Koike and M. Akita, Angew. Chem., Int. Ed., 2012, 51, 9567.

18 P. McDevitt and M. Vittimberga Bruno, J. Heterocycl. Chem., 2009, 27, 1903.

19 For a recent review on EDA complex, see:C. G. S. Lima, T. de M. Lima, M. Duarte, I. D. Jurberg and M. W. Paixão, ACS Catal., 2016, 6, 1389.

20 For recent examples on EDA-enabled radical trifluoromethylation, see $(a) \mathrm{H}$. Jiang, Y. He, Y. Cheng and S. Yu, Org. Lett., 2017, 19, 1240; (b) Y. Cheng and S. Yu, Org. Lett., 2016, 18, 2962; (c) Q. Guo, M. Wang, H. Liu, R. Wang and Z. Xu, Angew. Chem., Int. Ed., 2018, 57, 4747; (d) M. Zhu, K. Zhou, X. Zhang and S.-L. You, Org. Lett., 2018, 20, 4379.

21 H. Wang, Q. Xu and S. Yu, Org. Chem. Front., 2018, 5, 2224. 22 J. G. Traynham, Chem. Rev., 1979, 79, 323. 